\title{
Cannabis use and misuse prevalence among people with psychosis
}

\author{
BOB GREEN, ROSS YOUNG and DAVID KAVANAGH
}

\begin{abstract}
Background Increasing attention has been given by researchers to cannabis use in individuals with psychosis. As psychoses are relatively low-prevalence disorders, research has been mostly been restricted to small-scale studies of treatment samples. The reported prevalence estimates obtained from these studies vary widely.
\end{abstract}

\begin{abstract}
Aims To provide prevalence estimates based on larger samples and to examine sources of variability in prevalence estimates across studies.
\end{abstract}

\section{Method Data from 53 studies of treatment samples and 5 epidemiological studies were analysed.}

\section{Results Based on treatment sample data, prevalence estimates were calculated for current use (23.0\%), current misuse (11.3\%), 12-month use (29.2\%), I2- month misuse (18.8\%), lifetime use (42.1\%) and lifetime misuse (22.5\%). \\ Epidemiological studies consistently reported higher cannabis use and misuse prevalence in people with psychosis.}

\section{Conclusions The factor most consistently associated with increased odds of cannabis prevalence was specificity of diagnosis. Factors such as consumption patterns and study design merit further consideration.}

\section{Declaration of interest None.}

Substance use is widespread in the community (Costa e Silva, 2002). Cannabis is the most widely used illegal substance in Europe (European Monitoring Centre for Drugs and Drug Addiction, 2001), the USA (Substance Abuse and Mental Health Services Administration, 2001) and Australia (Australian Institute of Health and Welfare, 2002). Studies by Arseneault et al (2002), van Os et al (2002) and Zammit et al (2002) have reported an association between cannabis use and later psychosis. However, sharp increases in cannabis use have not been reflected in an increased prevalence of schizophrenia (Degenhardt et al, 2003). Also, a notable feature of the available literature has been the conflicting findings on the prevalence of substance use and associated outcomes on psychosis (Rabinowitz et al, 1998). The conflicting results have been attributed to factors such as sample composition (Mueser et al, 1990; Blanchard et al, 2000), country (Hambrecht \& Häfner, 1996), recruitment source (Mueser et al, 1990; Hambrecht \& Häfner, 1996; Fowler et al, 1998) and issues associated with diagnosis and method of data collection (Mueser et al, 1990; Hambrecht \& Häfner, 1996; Fowler et al, 1998; Blanchard et al, 2000). However, little research has been undertaken into factors contributing to the variability in prevalence estimates. The aim of our review is to obtain more reliable estimates of the prevalence of cannabis use based on larger samples, to examine factors that may be associated with variability in prevalence estimates and to compare prevalence estimates of individuals with and without psychosis.

\section{METHOD}

We examined reports of cannabis use and misuse prevalence, and whether the variability in these prevalence estimates was associated with factors identified by the researchers as potentially important. These factors included age and percentage of males in studies, median year of data collection, geographic area, recruitment source, first-episode status, specificity of diagnosis of psychosis and use of standard diagnostic classification criteria.

\section{Inclusion criteria}

Citations and academic databases were searched to identify English-language studies published between 1990 and 2002 which might contain data on the use or misuse of cannabis by people diagnosed with psychosis, schizophrenia-spectrum disorders or schizophrenia. Search terms used in PsycInfo and Medline were CANNABIS, MARIHUANA, MARIJUANA or HASHISH combined with SCHIZOPHRENIA, PSYCHOSIS or PSYCHOTIC. A second search was conducted using the term DUAL DIAGNOSIS. Where possible the authors of studies were contacted to identify whether specific information on cannabis and psychosis or schizophrenia was available. We identified 164 clinical studies that might have contained information on cannabis use and psychosis. The following review is based on 53 studies that met the inclusion criteria. In addition, five epidemiological studies that met the inclusion criteria were analysed separately.

In-patient and community patient studies were included if the prevalence of cannabis use or misuse among patients with psychosis, schizophrenia-spectrum disorders or schizophrenia could be calculated (e.g. studies were excluded if there was no breakdown by diagnosis or it was not clear whether all patients had psychotic symptoms); information was available regarding the prevalence interval used; substance use was not an inclusion criterion; the study did not oversample by age, gender or other criteria; and patients were only included once. Research on the same sample was not included twice for the same prevalence interval. Where a study reported prevalence by psychosis in general, as well as by subgroups such as schizophrenia, the more specific information was selected.

For the purpose of this review, misuse (including dependence) was the focus, since specific dependence data were not frequently reported. One study (Duke et al, 2001) reporting misuse was included with the studies reporting use, since 'misuse' was defined as 'any use'. Three time intervals for reporting prevalence of cannabis 
use and misuse were examined. Studies that reported prevalence in terms of use or misuse at a baseline assessment or in a 6-month period were categorised as current use or misuse. Studies that reported prevalence in terms of a 12-month to 18-month period were categorised as 12-month prevalence studies, whereas studies reporting any use or misuse ever were categorised as lifetime studies.

\section{Analysis}

Three sets of analyses were conducted. The first analysis involved the calculation of current, 12-month and lifetime prevalence estimates. For each prevalence interval (e.g. current use), the total number of reported cannabis users in studies that contained current use data was divided by the total sample size of the respective studies to calculate a weighted average.

To examine potential sources of variability in prevalence estimates, four multivariate analyses were performed. The respective prevalence interval (e.g. lifetime misuse) was the dependent variable and the following variables were entered as independent variables: recruitment source (whether study participants were recruited from a hospital, community setting or a combination of both); geographic area (studies were grouped as being conducted in either Australasia, continental Europe, North America or the UK); use of standardised substance misuse classification criteria (criteria reflecting an ICD or DSM diagnosis, as opposed to criteria devised by study authors); specificity of the diagnosis of psychosis (psychosis, schizophreniaspectrum disorders or schizophrenia only) and first-episode status (a specific firstepisode sample or not). Average age of the study samples, percentage of males in a study and the median year of data collection for each study were covariates. Missing values for average age and percentage of males resulted in some studies not being included in the multivariate analyses (Table 1). Multinomial logistic regression, which can be used to analyse dichotomous variables, was selected in preference to logistic regression for the analyses, because it has the advantage of calculating the likelihood ratio test for each individual independent variable (Menard, 2001). The likelihood ratio test is useful for determining the significance of variables included in a logistic regression model. The odds ratios reported in Tables 4 and 5 refer to
Table I Studies included in the analyses of clinical data

\begin{tabular}{|c|c|c|}
\hline Study & Prevalence data & $\begin{array}{l}\text { Study distinguished between } \\
\text { misuse and dependence }\end{array}$ \\
\hline Arndt et al (1992) & Lifetime misuse & No \\
\hline Bersani et al (2002) & Lifetime misuse, lifetime use & No \\
\hline Brewer et al (200 I) & Current use & No \\
\hline Cantor-Graae et al (200 I) & Lifetime misuse & No \\
\hline Cantwell et al (1999) & 12-month misuse & No \\
\hline Carr et al (2002) & Lifetime misuse, 12-month use & No \\
\hline Chouljian et al (1995) & Current misuse & No \\
\hline Claassen et al (1997) & Urine test & No \\
\hline Condren et al (200 I) & Lifetime misuse & No \\
\hline DeQuardo et al (1994) & Lifetime misuse & No \\
\hline Dervaux et al (200I) & Lifetime misuse & No \\
\hline Diwan et al (1998) & Current use, lifetime use & No \\
\hline Dixon et al (1991) & Lifetime misuse & No \\
\hline Duke et al (200I) & Current use, lifetime use & No \\
\hline Fowler et al (1998) & $\begin{array}{l}\text { Current use and misuse, urine test, lifetime } \\
\text { use and misuse }\end{array}$ & Yes \\
\hline Gearon et al (200 I) & Lifetime misuse & No \\
\hline Graham et al (200 I) & 12-month use and misuse & Yes \\
\hline Gut-Fayand et al (200I) & Lifetime misuse & Yes \\
\hline Hambrecht \& Häfner (1996) & Lifetime misuse & No \\
\hline Jablensky et al (2000) & Lifetime use and misuse & No \\
\hline Kamali et al (2000) & Current misuse, lifetime misuse & No \\
\hline King et al (1994)' & Urine test, lifetime use & No \\
\hline Kirkpatrick et al (1996) & $\begin{array}{l}\text { Current use and misuse, lifetime use and } \\
\text { misuse }\end{array}$ & No \\
\hline Kovasznay et al (1997) & Current use & No \\
\hline Krausz et al (1996)' & Lifetime use and misuse & No \\
\hline Ley et al (2002) & Urine test & No \\
\hline Martinez-Arevalo et al (1994) & Current use, lifetime use & No \\
\hline Mathers et al (199I)' & Urine test, lifetime use & No \\
\hline McCreadie (2002) & Lifetime misuse, 12-month use and misuse & No \\
\hline McGuire et al (1994) & Urine test & No \\
\hline Menezes et al (1996) & Lifetime use, 12-month use and misuse & No \\
\hline Modestin et al (1997)' & Current use, urine test & No \\
\hline Mueser et al (1990) & Current and lifetime misuse & No \\
\hline Mueser et al (1992) & Lifetime misuse & No \\
\hline Mueser et al (2000) & Lifetime misuse & No \\
\hline Negrete \& Gill (1999) & Current use and misuse & No \\
\hline Núñez \& Gurpegui (2002) & Urine test & No \\
\hline Peralta \& Cuesta (1992) & 12-month misuse & No \\
\hline Rabinowitz et al (1998) & Lifetime misuse & No \\
\hline Sembhi \& Lee (1999) & Current and lifetime use, urine test & No \\
\hline Sevy et al (200I) & Lifetime misuse & Yes \\
\hline Shaner et al (1993) & Current misuse & No \\
\hline Shumway et al (1994) & 12-month use & No \\
\hline Sokolski et al (1994) & Lifetime misuse & No \\
\hline Soyka et al (1993) & Current and lifetime misuse & No \\
\hline Steadman et al (1998) & Current and lifetime use & No \\
\hline Veen et al (2002) & Current and lifetime use, 12-month misuse & No \\
\hline Verdoux et al (1999) & Current use, lifetime misuse, urine test & No \\
\hline Warner et al (1994) & Current and lifetime use & No \\
\hline Wolford et al (1999) & Urine test & No \\
\hline Wright et al (200I) & Current misuse, lifetime and I2-month use & No \\
\hline Zaretsky et al (1993)' & Current use & No \\
\hline Ziedonis \& Trudeau (1997) & Current misuse & No \\
\hline
\end{tabular}

I. Study excluded from multivariate analysis because of missing data on age or gender. 
Table 2 Prevalence of cannabis use as a weighted average

\begin{tabular}{lccc}
\hline Prevalence interval & $\begin{array}{c}\text { Number of studies } \\
(\text { sample size) }\end{array}$ & $\begin{array}{c}\text { Weighted average } \\
\%(\text { s.e.m. })\end{array}$ & $\begin{array}{c}\text { Prevalence range } \\
\text { of studies } \\
\%\end{array}$ \\
\hline Current & $14(n=1695)$ & $23.1(1.0)$ & $4.5-81.1$ \\
I2-month & $6(n=1064)$ & $29.2(1.4)$ & $10.0-45.8$ \\
Lifetime & $15(n=3119)$ & $42.2(0.9)$ & $19.2-89.1$ \\
\hline
\end{tabular}

Table 3 Prevalence of cannabis misuse as a weighted average

\begin{tabular}{lccc}
\hline Prevalence interval & $\begin{array}{c}\text { Number of studies } \\
\text { (sample size) }\end{array}$ & $\begin{array}{c}\text { Weighted average } \\
\% \text { (s.e.m.) }\end{array}$ & $\begin{array}{c}\text { Prevalence range } \\
\text { of studies } \\
\%\end{array}$ \\
\hline Current & $11(n=2173)$ & $11.3(0.7)$ & $1.9-20.8$ \\
12-month & $6(n=1102)$ & $18.7(1.2)$ & $3.5-32.4$ \\
Lifetime & $26(n=4553)$ & $22.5(0.6)$ & $5.5-54.9$ \\
\hline
\end{tabular}

the respective increase or decrease in the odds of cannabis use or misuse associated

The third analysis compared prevalence estimates among individuals with and without psychosis in community population studies. Uncorrected odds ratios were calculated for epidemiological studies using data provided by the respective study authors. All analyses were performed using the Statistical Package for the Social Sciences, version 10.

\section{RESULTS}

\section{Cannabis use and misuse prevalence estimates from treatment samples}

Tables 2 and 3 display prevalences of current, 12-month and lifetime cannabis use and misuse, respectively. Few studies have examined use and misuse in the same study. The average percentage of people using cannabis whose use was classified as 'misuse' was $42.9 \%$ for current use, $44.7 \%$ for 12 -month use and $53.5 \%$ for lifetime use. Most studies reporting the prevalence of cannabis misuse did not distinguish between misuse and dependence (see Table 1). Of the four studies that provided data on misuse and dependence, three reported that over $75 \%$ of those with cannabis misuse met the criteria for misuse, rather than dependence. In contrast, the fourth study reported that $78.6 \%$ of with each independent variable. patients with lifetime use and $68.0 \%$ of those with current use were diagnosed with dependence rather than misuse. The age and gender compositions of this latter study and the other community-based study with misuse-dependence data were similar. However, the study diagnoses were based, respectively, on data collected by a trained research assistant who administered the structured clinical interview for DSM-III-R, and on ratings made by keyworkers on scales based on DSM-IV criteria.

Studies that used criteria from a standardised classification system reported a prevalence of $22.1 \%$ for lifetime misuse and $19.1 \%$ for 12 -month misuse. The respective prevalence rates for lifetime misuse and 12-month misuse reported by the studies that did not use criteria from a standardised classification system were $25.4 \%$ and $17.7 \%$. All studies reporting current misuse had used criteria from a DSM or ICD) to make this diagnosis.

\section{Prevalence estimates obtained from urine testing of treatment samples}

The prevalence of cannabis use detected by urine testing was $12.3 \%$ (s.e.m. $=0.9$ ). This was based on a sample of 1460 pooled from 12 studies. Information on the cut-off criteria used to determine the presence of cannabinoids in urine was reported in only seven of the available studies. Criteria ranged from $20 \mathrm{ng} / \mathrm{ml}$ to $100 \mathrm{ng} / \mathrm{ml}$. The respective percentages of positive urine tests were $12.0 \%$ at $20 \mathrm{ng} / \mathrm{ml}$ (three studies), $31.4 \%$ at $35 \mathrm{ng} / \mathrm{ml}$ (one study), $14.6 \%$ at standardised classification system (e.g.

Table 4 Multinomial logistic regression of variables associated with cannabis use

\begin{tabular}{|c|c|c|c|c|c|c|}
\hline \multirow[t]{2}{*}{ Variables } & \multicolumn{3}{|c|}{ Current use $(n=1500)$} & \multicolumn{3}{|c|}{ Lifetime use $(n=2435)$} \\
\hline & Odds ratio & $(95 \% \mathrm{Cl})$ & $P$ & Odds ratio & $(95 \% \mathrm{Cl})$ & $P$ \\
\hline Average age of sample & 0.88 & $(0.80-0.96)$ & 0.004 & 0.94 & $(0.91-0.96)$ & $<0.001$ \\
\hline Percentage of males & 1.06 & $(1.03-1.09)$ & $<0.001$ & 1.04 & $(1.03-1.05)$ & $<0.001$ \\
\hline \multicolumn{7}{|l|}{ Geographic area } \\
\hline Australasia & 1.56 & $(0.06-38.04)$ & NS & 1.70 & $(1.38-2.10)$ & $<0.001$ \\
\hline Europe (continental) & 0.78 & $(0.05-11.80)$ & NS & 0.91 & $(0.58-1.43)$ & NS \\
\hline North America & 1.25 & $(0.08-18.71)$ & NS & 1.53 & $(1.14-2.05)$ & 0.004 \\
\hline$U^{\prime}$ & 1.00 & & & & & \\
\hline Median year data collected & 1.05 & $(0.97-1.14)$ & NS & 0.78 & $(0.75-0.8 I)$ & $<0.001$ \\
\hline \multicolumn{7}{|l|}{ Specificity of diagnosis } \\
\hline Psychosis & 5.49 & $(2.98-10.11)$ & $<0.001$ & 5.17 & $(4.22-6.33)$ & $<0.001$ \\
\hline Schizophrenia spectrum & 2.40 & $(1.05-5.47)$ & 0.038 & 1.58 & $(1.24-2.02)$ & $<0.001$ \\
\hline Schizophrenia' & 1.00 & & & & & \\
\hline \multicolumn{7}{|l|}{ Recruitment source } \\
\hline Mixed & 3.90 & $(1.25-12.15)$ & 0.019 & 0.23 & $(0.17-0.31)$ & $<0.00$ I \\
\hline Community & 1.44 & $(0.75-2.76)$ & NS & 0.56 & $(0.43-0.74)$ & $<0.001$ \\
\hline Hospital' & 1.00 & & & & & \\
\hline \multicolumn{7}{|l|}{ First episode status } \\
\hline Not first episode & 1.68 & $(1.03-2.74)$ & 0.038 & 0.11 & $(0.08-0.15)$ & $<0.001$ \\
\hline First episode ${ }^{1}$ & 1.00 & & & & & \\
\hline
\end{tabular}

I. Reference category. 
Table 5 Multinomial logistic regression of variables associated with cannabis misuse

\begin{tabular}{|c|c|c|c|c|c|c|}
\hline \multirow[t]{2}{*}{ Variables } & \multicolumn{3}{|c|}{ Current misuse $(n=2173)$} & \multicolumn{3}{|c|}{ Lifetime misuse $(n=4078)$} \\
\hline & $\begin{array}{l}\text { Odds } \\
\text { ratio }\end{array}$ & $(95 \% \mathrm{Cl})$ & $P$ & $\begin{array}{l}\text { Odds } \\
\text { ratio }\end{array}$ & $(95 \% \mathrm{Cl})$ & $P$ \\
\hline Average age of sample & I.II & $(1.06-1.17)$ & $<0.00 \mathrm{I}$ & 1.01 & $(0.97-1.06)$ & NS \\
\hline Percentage of males & 1.03 & $(1.01-1.06)$ & 0.015 & 1.02 & $(1.01-1.04)$ & 0.004 \\
\hline \multicolumn{7}{|l|}{ Geographic area } \\
\hline Australasia & 1.53 & $(0.52-4.49)$ & NS & 2.13 & $(1.44-3.17)$ & $<0.001$ \\
\hline Europe (continental) & 0.09 & $(0.03-0.27)$ & $<0.001$ & 1.00 & $(0.49-2.04)$ & NS \\
\hline North America & 0.22 & $(0.08-0.58)$ & 0.002 & $\mathrm{I} .84$ & $(0.95-3.54)$ & NS \\
\hline UK' & 1.00 & & & 1.00 & & \\
\hline Median year data collected & 0.93 & $(0.84-I .03)$ & NS & 1.04 & $(\mathrm{I} .0 \mathrm{I}-\mathrm{I} .08)$ & 0.028 \\
\hline \multicolumn{7}{|l|}{ Criteria of misuse } \\
\hline Non-standardised criteria & & & & 1.54 & $(1.11-2.14)$ & 0.009 \\
\hline Standardised criteria ${ }^{\prime}$ & 2 & & & 1.00 & & \\
\hline \multicolumn{7}{|l|}{ Specificity of diagnosis } \\
\hline Psychosis & & & & 1.53 & $(0.76-3.09)$ & NS \\
\hline Schizophrenia spectrum & 10.43 & $(2.93-37.06)$ & $<0.001$ & 1.90 & $(1.27-2.84)$ & 0.002 \\
\hline Schizophrenia' & 1.00 & & & 1.00 & & \\
\hline \multicolumn{7}{|l|}{ Recruitment source } \\
\hline Mixed & 0.51 & $(0.22-1.17)$ & NS & 0.68 & $(0.49-0.95)$ & 0.023 \\
\hline Community & 2 & & & 1.48 & $(0.79-2.75)$ & NS \\
\hline Hospital' & 1.00 & & & 1.00 & & \\
\hline \multicolumn{7}{|l|}{ First episode status } \\
\hline Not first episode & & & & 1.47 & $(0.85-2.54)$ & NS \\
\hline First episode' & 2 & & & 1.00 & & \\
\hline
\end{tabular}

I. Reference category

2. No study available for comparison.
$50 \mathrm{ng} / \mathrm{ml}$ (one study) and $10.0 \%$ at $100 \mathrm{ng} /$ $\mathrm{ml}$ (two studies).

\section{Multivariate analysis}

The results of the multinomial logistic regression are reported in Tables 4 and 5 . Variables were initially entered in the following order: recruitment source, geographic area, use of standardised substance misuse classification criteria, specificity of diagnosis of psychosis, and first-episode status. Average age of the study samples, percentage of males in a study and the median year of data collection for each study were covariates. The largest odds were consistently associated with a broader diagnosis of psychosis (e.g. psychosis or schizophrenia-spectrum disorder compared with schizophrenia). The significance levels obtained for each of the four models indicated that the independent variables significantly contributed to each model, but they were weak predictors as indicated by the resulting McFadden statistics (ranged from 0.019 to 0.155 ) which are analogues of $R^{2}$ (Menard, 2001). Each analysis obtained a statistically significant model chi-square.

\section{Cannabis use and misuse prevalence in epidemiological studies}

Table 6 lists the prevalence estimates obtained from epidemiological studies. All

Table 6 Prevalence of cannabis use and misuse estimates from epidemiological studies

\begin{tabular}{|c|c|c|c|c|c|c|}
\hline & \multirow[t]{2}{*}{ Study sample } & \multicolumn{2}{|c|}{$\begin{array}{l}\text { Non-psychosis } \\
\text { group }\end{array}$} & \multicolumn{2}{|c|}{$\begin{array}{l}\text { Psychosis } \\
\text { group }\end{array}$} & \multirow[t]{2}{*}{ Odds ratio $(95 \% \mathrm{Cl})$} \\
\hline & & $\begin{array}{c}\text { Preva- } \\
\text { lence } \\
(\%)\end{array}$ & $\begin{array}{c}\text { Total } \\
\text { sample } \\
\text { size } \\
(n)\end{array}$ & $\begin{array}{c}\text { Preva- } \\
\text { lence } \\
(\%)\end{array}$ & $\begin{array}{c}\text { Total } \\
\text { sample } \\
\text { size } \\
(n)\end{array}$ & \\
\hline \multicolumn{7}{|l|}{ Lifetime use } \\
\hline Coulthard et al (2002) & UK household sample (aged 16-74 years) & 21.9 & 8484 & 34.5 & 58 & $1.88(1.09-3.24)$ \\
\hline van Os et al (2002) & Dutch household sample (aged I8-64 years) & 9.4 & 6968 & 18.7 & 107 & $2.21(1.35-3.61)$ \\
\hline Zammit et al (2002) & $\begin{array}{l}\text { Swedish conscripts (cohort aged } 18-20 \text { years at baseline: } \\
20 \text {-year follow-up) }\end{array}$ & 11.0 & 47703 & 17.7 & 779 & $1.74(1.45-2.10)$ \\
\hline \multicolumn{7}{|l|}{ 12-month use } \\
\hline Arseneault et al (2002) & New Zealand birth cohort (aged 26 years) & 50.6 & 934 & 69.4 & 36 & $2.22(1.08-4.55)$ \\
\hline Coulthard et al (2002) & UK household sample (aged 16-74 years) & 8.0 & 8484 & 12.1 & 58 & $\mathrm{I} .58(0.7 \mathrm{I}-3.48)^{\prime}$ \\
\hline Degenhardt \& Hall (200I) & Australian household sample (aged I8-50 years) & 10.5 & 6623 & 31.3 & 99 & $3.98(2.59-6.14)$ \\
\hline \multicolumn{7}{|l|}{ I2-month misuse } \\
\hline Arseneault et al (2002) & New Zealand birth cohort (aged 26 years) & 8.6 & 934 & 27.8 & 36 & $4.11(1.91-8.82)$ \\
\hline Coulthard et al (2002) & UK household sample (aged 16-74 years) & 2.5 & 8484 & 6.9 & 58 & $2.92(1.05-8.13)^{2}$ \\
\hline Degenhardt \& Hall (200I) & Australian household sample (aged I8-50 years) & 3.3 & 6623 & 16.2 & 99 & $5.86(3.37-10.18)$ \\
\hline
\end{tabular}

I. Not statistically significant.

2. Statistically significant when cut-off was on symptom of dependence. Odds ratio was not statistically significant when the cut-off was two dependence symptoms.
. 
the studies showed higher odds of cannabis use or misuse for people with psychosis. The lifetime use estimates (van Os et al, 2002; Zammit et al, 2002) were lower than the lifetime use estimates in any study reported in Table 2. The 12-month prevalence use and misuse estimates for the psychosis group in the Degenhardt $\&$ Hall (2001) study are comparable to the estimates in Tables 2 and 3.

The standard reference on cannabis misuse prevalence in the community among people with schizophrenia is the Epidemiologic Catchment Area study (Regier et al, 1990). The unweighted prevalence of a lifetime DSM-III cannabis misuse diagnosis among people with schizophrenia in this latter study was $19.7 \%, 13.4 \%$ in the household sample and a $36.2 \%$ prevalence in the institutional sample (D. Rae, personal communication, 2002).

\section{DISCUSSION}

A systematic review of published studies found that the prevalence of misuse of cannabis was approximately half that of its use, and that 12-month misuse prevalence provided a sound indication of lifetime misuse prevalence. Current misuse prevalence displayed the least variation across studies. These estimates provide a benchmark to evaluate prevalence reported in subsequent research, as well as to assist with decisions regarding the selection of appropriate prevalence intervals. The prevalence estimates were based on a total sample that was larger than has previously been reported.

\section{Study recruitment source}

We found no consistent pattern of increased or decreased odds associated with recruitment source, although analysis of epidemiological data indicated a consistent pattern of increased odds of cannabis use and misuse associated with psychosis. Despite different study designs, the prevalence estimates obtained for people with psychosis from the epidemiological studies were consistently higher than the estimates for non-psychosis samples. Although the low lifetime prevalence use in the Swedish birth cohort study (Zammit et al, 2002) could be attributed to the fact that the data were collected in 1969-70, the prevalence estimate was similar to the Dutch household study (van Os et al, 2002) which collected data in 1996. The lifetime prevalence in the latter study was almost half the current use prevalence reported in a population-based first-incidence Dutch psychosis study (Veen et al, 2002). Given that cannabis is readily available in The Netherlands, the low lifetime prevalence reported in the epidemiological study supports the hypothesis that prevalence estimates may be inflated in clinical samples. In contrast, the Australian household study (Degenhardt \& Hall, 2001) obtained 12-month prevalence estimates similar to those reported in Tables 2 and 3.

Epidemiological studies have important advantages over clinical samples in relation to sample size and representativeness; however, with the exception of the Swedish birth cohort study (Zammit et al, 2002), the number of people in the epidemiological studies with psychosis was relatively small. Additionally, across the studies there was variation in the methods used and clinical experience of the researchers employed to identify individuals with psychosis.

In relation to treatment samples, only two studies provided prevalence estimates for samples from different sources (Soyka et al, 1993; Carr et al, 2002). In the earlier study differences in the prevalence estimates might be accounted for by differences in admission criteria and functions of the hospitals, and the fact that the university sample had a significantly lower percentage of males - indeed, the lowest percentage of males of any study reviewed.

\section{Diagnostic criteria and data collection}

The most consistent finding across the multivariate analyses was the increased odds associated with a broader diagnosis (e.g. psychosis compared with schizophrenia). This suggests that a fundamental criterion for inclusion in a study might account for some of the variation in prevalence estimates. One explanation for the increased odds associated with the broader diagnosis of psychosis is the possible inclusion of individuals with drug-induced psychoses.

The criteria for diagnosing substance misuse could only be examined for lifetime misuse, as all studies of current misuse had adopted some form of standardised criteria. It was originally intended to examine prevalence in terms of the method used to diagnose substance misuse; however, the diversity of approaches in reviewed studies (e.g. the use of some questions from structured interviews within clinical interviews) made categorising studies using this criterion problematic.

Differences in prevalence have been accounted for by both criteria and information variance (Klerman, 1985). The importance of considering the criteria used comes from a study that compared substance use diagnoses in a first-episode patient sample made by a research team with those made by clinicians. The research team and clinicians diagnosed cannabis use disorder in $8.5 \%$ and $33.3 \%$ of the patients respectively. Generally, disagreement was attributed to differences in applying diagnostic criteria rather than differences in the information that was available (Fennig et al, 1996). In contrast, the differences in prevalence estimates reported in the Epidemiologic Catchment Area and National Comorbidity Survey studies have been attributed to information variance (Regier et al, 1998; Narrow et al, 2002). This information variance was considered to be due to differences in the nature of interviews that were employed.

Study design has also been reported to affect disclosure of sensitive information (Kessler et al, 2000). Inconsistencies in reporting have been found to be greater among people using cocaine compared with those using cannabis, with inconsistent accounts of lifetime use more likely by people with lower levels of use (Fendrich \& Mackesy Amiti, 1995). Although the presence of underreporting can be difficult to determine, patient self-report has been found to accord with urine tests (Fowler et al, 1998) and collateral sources (Carey \& Simons, 2000). However, a study by Swartz et al (2003) found that cannabis prevalence differed according to the method of data collection: self-report $9.4 \%$, urine testing $6.4 \%$ and hair analysis $19.9 \%$. The prevalence obtained by hair analysis is closest to the current use reported in Table 2.

Prevalence estimates obtained by urine testing raise two issues of interest. First, prevalence was not markedly lower when a higher cut-off criterion was used. Second, some studies noted that patients who reported cannabis use did not return a positive result (Condren et al, 2001). A similar finding has been reported in relation to hair analysis (Selten et al, 2002). A factor accounting for the former finding and differences in prevalence is likely to be the frequency of cannabis use and the time interval from use to testing. At the $20 \mathrm{ng} / \mathrm{ml}$ cut-off level, infrequent cannabis users 
would on average be expected to test positive 2-3 days after cannabis use, whereas frequent users would on average test positive for 9-12 days (Kelly \& Jones, 1992). Information on when testing was conducted (e.g. average days after admission), method of testing and cut-off criteria employed are necessary to evaluate more fully cannabis prevalence data based on urine testing.

\section{Age and gender}

Age was associated with slightly increased odds of misuse (current and lifetime) and decreased odds of use (current and lifetime); higher percentages of males in a study sample were associated with a small increase in odds of use and misuse across the prevalence intervals. Although two studies were identified that did not find differences in either age or gender between those using cannabis and other patients (Peralta \& Cuesta, 1992; Sembhi \& Lee, 1999), a number of studies have found that cannabis use and misuse are associated with younger age (Mueser et al, 1990, 2000; Mathers et al, 1991; Bersani et al, 2002; Veen et al, 2002) and being male (Mueser et al, 1990, 1992, 2000; Mathers et al, 1991; Negrete \& Gill, 1999; Núñez \& Gurpegui, 2002; Veen et al, 2002). The findings from our review also suggest that the age and gender composition of study samples would be expected to contribute to variation in prevalence estimates across studies.

\section{Year of data collection}

No consistent association was found between prevalence and median year of data collection. A review by Cuffel (1992) reported an association between the year of data collection and alcohol or amphetamine use; in that review, more recent studies reported higher prevalence. The studies included by Cuffel were from the period 1960-1991 and there were insufficient studies on cannabis to examine this relationship. Our review included studies published between 1990 and 2002, which collected data between 1983 and 2002. It may be the case that more time is required to determine a temporal pattern, or that other factors may interact with time period, such as changes in cannabis availability.

An illustration of how prevalence estimates vary over time is illustrated by two US studies. The first study, which collected data between 1983 and 1986 (Mueser et al, $1990)$, reported a $40 \%$ lifetime prevalence of cannabis use. A subsequent study from the same area (Mueser et al, 1992) that collected data between 1986 and 1990 reported a lifetime prevalence of $15.7 \%$. These findings need to be considered in the context of the decreasing use of cannabis reported in the USA in the 1980s and the increased use of cocaine in the same period (Costa e Silva, 2002).

\section{Geographic area}

No consistent association was found between prevalence of use or misuse and geographic area. Where prevalence estimates vary by geographic area this may be due to factors such as drug availability or changing trends in drug preference, as well as preferences for different research designs.

\section{Limitations of our study}

A limitation of our review is that studies of varying methodologies and methodological rigour were combined. The impact of different methods on prevalence estimates is difficult to determine and requires further attention; the issue of study quality was addressed by only including studies that met the inclusion criteria, especially the requirement that adequate detail was available. Pooling studies from different countries and time periods may have been problematic; however, these variables were included in the logistic regression and specific prevalence estimates for these variables were provided separately.

\section{Future research}

This review produced cannabis prevalence estimates based on the most comprehensive data to date and systematically examined factors that might account for the variation in prevalence estimates across studies. The increased odds of cannabis use and misuse among the population-based studies supports the view that the high prevalence rates in treatment samples are not simply a sampling artefact. Among the treatment samples, specificity of the diagnosis of psychosis was the variable most consistently associated with increased odds of cannabis use or misuse. The percentage of male participants in the study samples was associated with a small increase in odds of use and misuse, whereas age was associated with increased odds of misuse and decreased odds of use. This was the one consistent difference between the use and misuse models. As the majority of variance in predicting use and misuse was not accounted for by the common methodological variables included in this review, a more finely grained examination of the impact of different data collection tools is required. It will be important to examine additional factors such as motivation, disorder severity, craving and consumption levels, which might account for continued cannabis use and misuse. Such research has both clinical and policy implications, particularly in countries with high prevalence estimates.

\section{ACKNOWLEDGEMENTS}

The assistance of cited authors and their colleagues who provided supplementary information is acknowledged, as is the assistance of Scott Menard, who provided advice on logistic regression.

\section{REFERENCES}

Arndt, S., Tyrrell, G., Flaum, M., et al (1992)

Comorbidity of substance abuse and schizophrenia: the role of pre-morbid adjustment. Psychological Medicine, 22, 379-388.

Arseneault, L., Cannon, M. C., Poulton, R., et al (2002) Cannabis use in adolescence and risk for adult psychosis: longitudinal prospective study. BMJ, 325, 1212-1213.

Australian Institute of Health and Welfare (2002) 2001 National Drug Strategy Household Survey: First Results. Canberra: Australian Institute of Health and Welfare.

Bersani, G., Orlandi, V., Kotzalidis, G. D., et al (2002) Cannabis and schizophrenia impact on onset, course, psychopathology and outcomes. European Archives of Psychiatry and Clinical Neuroscience, 252, 86-92.

Blanchard, J. J., Brown, S. A., Horan, W. P., et al (2000) Substance use disorders in schizophrenia: review, integration, and a proposed model. Clinical Psychology Review, 20, 207-234.

Brewer, W. J., Pantelis, C., Anderson, V., et al (200I) Stability of olfactory identification deficits in neuroleptic naive patients with first-episode psychosis. American Journal of Psychiatry, 158, 107-115.

Cantor-Graae, E., Nordstrom, L. G. \& McNeil, T. F. (200I) Substance abuse in schizophrenia: a review of the literature and a study of correlates in Sweden. Schizophrenia Research, 48, 69-82.

Cantwell, R., Brewin, J., Glazebrook, C., et al (1999) Prevalence of substance misuse in first-episode psychosis. British Journal of Psychiatry, 174, 150-153.

Carey, K. B. \& Simons, J. (2000) Utility of collateral information in assessing substance use among psychiatric outpatients. Journal of Substance Abuse, II, 139-147.

Carr, V. J., Lewin, T. J., Barnard, R. E., et al (2002) Comparisons between schizophrenia patients recruited 
from Australian general practices and public mental health services. Acta Psychiatrica Scandinavica, 105 346-355.

Chouljian, T. L., Shumway, M., Balancio, E., et al (1995) Substance use among schizophrenic outpatients: prevalence, course, and relation to functional status. Annals of Clinical Psychiatry, 7, 19-24.

Claassen, C. A., Gilfillan, S., Orsulak, P., et al (1997) Substance use among patients with a psychotic disorder in a psychiatric emergency room. Psychiatric Services, 48 353-358.

Condren, R. M., O'Connor, J. \& Browne, R. (200I) Prevalence and patterns of substance misuse in schizophrenia: a catchment area case-control study. Psychiatric Bulletin, 25, 17-20.

Costa e Silva, J. A. (2002) Evidence-based analysis of the worldwide abuse of licit and illicit drugs. Human Psychopharmacology, 17, |3|-140.

Coulthard, M., Farrell, M., Singleton, N., et al (2002) Tobacco, Alcohol and Drug Use and Mental Health. London: Stationery Office.

Cuffel, B. J. (1992) Prevalence estimates of substance abuse in schizophrenia and their correlates. Journal of Nervous and Mental Disease, 180, 589-592.

Degenhardt, L. \& Hall, W. (200I) The association between psychosis and problematical drug use among Australian adults: findings from the National Survey of Mental Health and Well-Being. Psychological Medicine 31, 659-668.

Degenhardt, L., Hall, W. \& Lynskey, M. (2003) Testing hypotheses about the relationship between cannabis use and psychosis. Drug and Alcohol Dependence, $7 \mathbf{I}$ $37-48$

DeQuardo, J. R., Carpenter, C. F. \& Tandon, R. (1994) Patterns of substance abuse in schizophrenia: nature and significance. Journal of Psychiatric Research, 28, 267-275.

Dervaux, A., Bayle, F. J., Laqueille, X., et al (200I) Is substance abuse in schizophrenia related to impulsivity, sensation seeking, or anhedonia. American journal of Psychiatry, 158, 492-494.

Diwan, A., Castine, M., Pomerleau, C. S., et al (1998) Differential prevalence of cigarette smoking in patients with schizophrenic vs mood disorders. Schizophrenia Research, 33, 113-118.

Dixon, L., Haas, G., Wieden, P. J., et al (1991) Drug abuse in schizophrenic patients: clinical correlates and reasons for use. American Journal of Psychiatry, 148 224-230.

Duke, P. J., Pantelis, C., McPhillips, M. A., et al (200I) Comorbid non-alcohol substance misuse among people with schizophrenia. British Journal of Psychiatry, I79, 509-513.

European Monitoring Centre for Drugs and Drug Addiction (200I) 2001 Annual Report on the State of the Drugs Problem in the European Union. Brussels: European Monitoring Centre for Drugs and Drug Addiction.

\section{Fendrich, M. \& Mackesy Amiti, M. E. (1995)}

Inconsistencies in lifetime cocaine and marijuana use reports: impact on prevalence and incidence. Addiction $90,111-118$

Fennig, S., Naisberg-Fennig, S., Craig, T. J., et al (1996) Comparison of clinical and research diagnoses of substance use disorders in a first admission psychotic sample. American Journal on Addictions, 5, 40-48.
Fowler, I. L., Carr, V. J., Carter, N. T., et al (1998) Patterns of current and lifetime substance use in schizophrenia. Schizophrenia Bulletin, 24, 443-455.

Gearon, J. S., Bellack, A. S., RachBeisel, J., et al (200I) Drug-use behaviour and correlates in people with schizophrenia. Addictive Behaviors, 26, 5I-6I.

Graham, H., Maslin, J., Copello, A., et al (200I) Drug and alcohol problems amongst individuals with severe mental health problems in an inner city area of the UK. Social Psychiatry and Psychiatric Epidemiology, 36, 448-455.

Gut-Fayand, A., Dervaux, A., Olié, J.-P., et al (200I) Substance abuse and suicidality in schizophrenia: a common risk factor linked to impulsivity. Psychiatry Research, 102, 65-72.

Hambrecht, M. \& Häfner, H. (1996) Substance abuse and the onset of schizophrenia. Biological Psychiatry, $\mathbf{4 0}$, II55-1163.

Jablensky, A., McGrath, J., Herman, H., et al (2000) Psychotic disorders in urban areas: an overview of the study on low prevalence disorders. Australian and New Zealand journal of Psychiatry, 34, 221-236.

Kamali, M., Kelly, L., Gervin, M., et al (2000) The prevalence of comorbid substance misuse and its influence on suicidal ideation among in-patients with schizophrenia. Acta Psychiatrica Scandinavica, 101, 452-456.

Kelly, P. \& Jones, R. T. (1992) Metabolism of tetrahydrocannabinol in frequent and infrequent marijuana users. Journal of Analytical Toxicology, 16 228-235

Kessler, R. C., Wittchen, H.-U., Abelson, J., et al (2000) Methodological issues in assessing psychiatric disorders with self-reports. In The Science of Self-Report Implications for Research and Practice (eds A. A. Stone, J. S. Turkkan, C. A. Bachrach, et al), pp. 229-255. Mahwah, NJ: Lawrence Erlbaum.

King, M., Coker, E., Leavey, G., et al (1994) Incidence of psychotic illness in London: comparison of ethnic groups. BM/, 309, $115-119$.

Kirkpatrick, B., Amador, X. F., Flaum, M., et al (1996) The deficit syndrome in the DSM-IV Field Trial: I. Alcohol and other drug abuse. Schizophrenia Research, 20, 69-77.

Klerman, G. (1985) Diagnosis of psychiatric disorders in epidemiologic field studies. Archives of General Psychiatry, 42, 723-724.

Kovasznay, B., Fletcher, J., Tanenberg-Karant, M., et al (1997) Substance abuse disorder and the early course of illness in schizophrenia and affective psychosis. Schizophrenia Bulletin, 23, 195-201.

Krausz, M., Haasen, C., Mass, R., et al (1996) Harmful use of psychotropic substances by schizophrenics: coincidence, patterns of use and motivation. European Addiction Research, 2, 11-16.

Ley, A., Jeffery, D., Ruiz, J., et al (2002)

Underdetection of comorbid drug use at acute psychiatric admission. Psychiatric Bulletin, 26, 248-25I.

Martinez-Arevalo, M. J., Calcedo-Ordonez, A. \& Varo-Prieto, J. R. (1994) Cannabis consumption as a prognostic factor in schizophrenia. British Journal of Psychiatry, 164, 679-68.

Mathers, D. C., Ghodse, A. H., Caan, A. W., et o (1991) Cannabis use in a large sample of acute psychiatric admissions. British Journal of Addiction, 86, 779-784

McCreadie, R. G. (2002) Use of drugs, alcohol and tobacco by people with schizophrenia: case-control study. British Journal of Psychiatry, 181, 321-325.
McGuire, P. K., Jones, P., Harvey, I., et al (1994) Cannabis and acute psychosis. Schizophrenia Research, I3 $161-168$

Menard, S. (200I) Applied Logistic Regression Analysis. Thousand Oaks, CA: Sage.

Menezes, P. R., Johnson, S., Thornicroft, G., et a (1996) Drug and alcohol problems among individuals with severe mental illnesses in south London. British Journal of Psychiatry, 168, 612-619.

Modestin, J., Nussbaumer, C., Angst, K., et al (1997) Use of potentially abusive psychotropic substances in psychiatric inpatients. European Archives of Psychiatry and Clinical Neuroscience, 247. 146-153.

Mueser, K. T., Yarnold, P. R., Levinson, D. F., et al (1990) Prevalence of substance abuse in schizophrenia: demographic and clinical correlates. Schizophrenia Bulletin, 16, 3I-56.

Mueser, K. T., Yarnold, P. R. \& Bellack, A. S. (1992) Diagnostic and demographic correlates of substance abuse in schizophrenia and major affective disorder. Acto Psychiatrica Scandinavica, 85, 48-55.

Mueser, K. T., Yarnold, P. R., Rosenberg, S. D., et al (2000) Substance use disorder in hospitalized severely mentally ill psychiatric patients: prevalence, correlates, and subgroups. Schizophrenia Bulletin, 26 179-192.

Narrow, W. E., Rae, D. S., Robins, L. N., et al (2002) Revised prevalence estimates of mental disorders in the United States. Archives of General Psychiatry, 59 II5-123.

Negrete, J. C. \& Gill, K. (1999) Cannabis and schizophrenia - an overview of the evidence to date. In Marihuana and Medicine (eds G. G. Nahas, K. M. Sutin, D. Harvey, et al), pp. 67I-68I. Totowa, NJ: Humana Press.

Núñez, L. A. \& Gurpegui, M. (2002) Cannabisinduced psychosis: a cross-sectional comparison with acute schizophrenia. Acute Psychiatrica Scandinavica, 105 173-178.

Peralta, V. \& Cuesta, M. J. (1992) Influence of cannabis abuse on schizophrenic psychopathology. Acta Psychiatrica Scandinavica, 85, 127-130.

Rabinowitz, J., Bromet, E. J., Lavelle, J., et al (1998) Prevalence and severity of substance use disorders and onset of psychosis in first-admission psychotic patients. Psychological Medicine, 28, |4II-1419.

Regier, D. A., Farmer, M. E., Rae, D. S., et al (1990) Comorbidity of mental disorders with alcohol and other drug abuse. Results from the Epidemiologic Catchment Area (ECA) Study. JAMA, 264 $2511-2518$

Regier, D. A., Kaelber, C.T., Rae, D. S., et al (1998) Limitations of diagnostic criteria and assessment instruments for mental disorders. Archives of General Psychiatry, 55, 109-115.

Selten, J.-P., Bosman, I., de Boer, D., et al (2002) Hair analysis for cannabinoids and amphetamines in a psychosis incidence study. European Neuropsychopharmacology, 12, 27-30.

Sembhi, S. \& Lee, J.W.Y. (1999) Cannabis use in psychotic patients. Australian and New Zealand journal of Psychiatry, 33, 529-532.

Sevy, S., Robinson, D. G., Solloway, S., et al (200I) Correlates of substance misuse in patients with first-episode schizophrenia and schizoaffective disorder. Acta Psychiatrica Scandinavica, 104, 367-374. 
Shaner, A., Khalsa, M. E., Roberts, L., et al

(1993) Unrecognized cocaine use among

schizophrenic patients. American Journal of Psychiatry, I50, 758-762.

Shumway, M., Chouljian, T. L. \& Hargreaves, W. A. (1994) Patterns of substance use in schizophrenia: a Markov modelling approach. Journal of Psychiatric Research, 28, 277-287.

Sokolski, K. N., Cummings, J. L., Abrams, B. I., et al (1994) Effects of substance abuse on

hallucination rates and treatment responses in chronic psychiatric patients. Journal of Clinical Psychiatry, 55, 380-387.

Soyka, M., Albus, M., Kathmann, N., et al (1993) Prevalence of alcohol and drug abuse in schizophrenic inpatients. European Archives of Psychiatry and Clinical Neuroscience, 242, 362-372.

Steadman, H. J., Mulvey, E. P., Monahan, J., et al (1998) Violence by people discharged from acute psychiatric inpatient facilities and by others in the same neighborhoods. Archives of General Psychiatry, 55, 393-401.

\section{Substance Abuse and Mental Health}

Services Administration (200I) Summary

of Findings from the 2000 National Household

Survey on Drug Abuse. Rockville, MD: Office of Applied

Studies.

Swartz, M. S., Swanson, J.W. \& Hannon, M. J. (2003) Detection of illicit substance use among persons with schizophrenia by radioimmunoassay of hair. Psychiatric Services, 54, 891-895.

\section{van Os, J., Bak, M., Hanssen, M., et al (2002)} Cannabis use and psychosis: a longitudinal populationbased study. American Journal of Epidemiology 156 319-327.

Veen, N., Selten, J.-P., Hoek, H. W., et al (2002) Use of illicit substances in a psychosis incidence cohort: comparison among different ethnic groups in the Netherlands. Acta Psychiatrica Scandinavica, 105 440-443.

Verdoux, H. L., Gonzales, B., Assens, F., et al (1999) Suicidality and substance misuse in first-admitted subjects with psychotic disorder. Acta Psychiatrica Scandinavica, 100, 389-395.

Warner, R., Taylor, D., Wright, J., et al (1994) Substance use among the mentally ill: prevalence, reasons for use, and effects on illness. American Journal of Orthopsychiatry, 64, 30-39.

Wolford, G. L., Rosenberg, S. D., Drake, R. E., et al (1999) Evaluation of methods for detecting substance use disorder in persons with severe

\section{CLINICAL IMPLICATIONS}

- The high prevalence of cannabis use and misuse among people with psychosis does not appear to be an artefact of sampling.

- Least variability in prevalence estimates was found when current misuse was diagnosed using a standardised assessment approach.

- For urine testing to be an effective means of determining current use, issues such as the interval between use and testing, cut-off levels and method need to be considered.

\section{LIMITATIONS}

- Studies of varying methodologies and methodological rigour were combined.

- Pooling studies from different countries and time periods may be problematic.

- A more fine-grained approach to examining how data collection differed across studies was not undertaken.

BOB GREEN, MSW, Community Forensic Mental Health Service, Brisbane; ROSS YOUNG, School of Psychology and Counselling, Faculty of Health, Queensland of University of Technology, Carseldine; DAVID KAVANAGH, PhD, Department of Psychiatry, Central Clinical Division, University of Queensland, Brisbane Australia

Correspondence: Bob Green, Community Forensic Mental Health Service, 42 Albert Street, Brisbane 400I, Australia. Tel: +6I (0)7 73221 25II; fax: +6I (0)7 73221 6060; e-mail:

bob_green@health.qld.gov.au

(First received 21 October 2003, final revision 16 November 2004, accepted 26 January 2005)

mental illness. Psychology of Addictive Behaviors, 13, 313-326.

Wright, S., Gournay, K., Glorney, E., et a

(200I) Dual diagnosis in the suburbs:

prevalence, need, and in-patient service use

Social Psychiatry and Psychiatric Epidemiology, 35,

297-304.

Zammit, S., Allebeck, P., Andreasson, S., et al (2002) Self reported cannabis use as a risk factor for schizophrenia in Swedish conscripts of 1969: historical cohort study. BMI, 325, I|99-120।.

Zaretsky, A., Rector, N. A., Seeman, M. V., et a (1993) Current cannabis use and tardive dyskinesia. Schizophrenia Research, II, 3-8.

Ziedonis, D. M. \& Trudeau, K. (1997) Motivation to quit using substances among individuals with schizophrenia: implications for a motivation-based treatment model. Schizophrenia Bulletin, 23, 229-238. 